\title{
Elastomeric Nanocomposite Based on Exfoliated Graphene Oxide and Its Characteristics without Vulcanization
}

\author{
Nasser Abdullah Habib, ${ }^{1,2}$ Buong Woei Chieng, ${ }^{3}$ Norkhairunnisa Mazlan, ${ }^{4}$ Umer Rashid, \\ Robiah Yunus, ${ }^{5}$ and Suraya Abdul Rashid ${ }^{1,5}$ \\ ${ }^{1}$ Materials Processing and Technology Laboratory, Institute of Advanced Technology, Universiti Putra Malaysia, 43400 Serdang, \\ Selangor, Malaysia \\ ${ }^{2}$ Department of Applied Sciences, University of Technology, 52 Al-Sina'a St., Baghdad, Iraq \\ ${ }^{3}$ Department of Chemistry, Faculty of Science, Universiti Putra Malaysia, 43400 Serdang, Selangor, Malaysia \\ ${ }^{4}$ Department of Aerospace Engineering, Universiti Putra Malaysia, 43400 Serdang, Selangor, Malaysia \\ ${ }^{5}$ Department of Chemical and Environmental Engineering, Faculty of Engineering, Universiti Putra Malaysia, 43400 Serdang, \\ Selangor, Malaysia
}

Correspondence should be addressed to Suraya Abdul Rashid; suraya_ar@upm.edu.my

Received 23 September 2016; Revised 3 January 2017; Accepted 24 January 2017; Published 13 March 2017

Academic Editor: Jae-Min Myoung

Copyright (C) 2017 Nasser Abdullah Habib et al. This is an open access article distributed under the Creative Commons Attribution License, which permits unrestricted use, distribution, and reproduction in any medium, provided the original work is properly cited.

\begin{abstract}
Rubber nanocomposites have emerged as one of the advanced materials in recent years. The aim of this work was to homogeneously disperse graphene oxide (GO) sheets into Nitrile Butadiene Rubber (NBR) and investigate the characteristics of GO/NBR nanocomposite without vulcanization. A suitable solvent was found to dissolve dry NBR while GO was exfoliated completely in an aqueous base solution using sonication. GO was dispersed into NBR at different loadings by solution mixing to produce unvulcanized GO/NBR nanocomposites. Scanning Electron Microscopy (SEM), Fourier-Transform Infrared Spectroscopy (FTIR), and X-Ray Diffraction (XRD) were used to characterize the samples. Furthermore, mechanical and electrical properties of unvulcanized GO/NBR nanocomposites were carried out to determine the influence of GO on the NBR properties. The results showed that the modulus of GO/NBR nanocomposite at $1 \mathrm{wt} \%$ of GO was enhanced by about $238 \%$ compared with unfilled NBR. These results provide insight into the properties of unvulcanized GO/NBR nanocomposite for application as coatings or adhesives.
\end{abstract}

\section{Introduction}

The exploration of elastomer properties has received significant attention amongst industrial and academic researchers. Synthetic rubbers have better engineering properties than natural rubber, which are useful for many applications. The most common type of synthetic rubber is Nitrile Butadiene Rubber (NBR), which is produced by the copolymerization of acrylonitrile and butadiene in an emulsion process. The molecules of acrylonitrile in NBR are linked with other molecules through free-radical initiators, which then forms its structure. NBR has a good resistance to a wide variety of nonpolar oils and solvents $[1,2]$. In general, fabrication of rubber includes mixing the rubber with some additives, vulcanization materials, and other agents through a complex process. It is attributed to the thermoset elastomers characteristics which are not the typically self-reinforced polymers. The properties of unvulcanized rubbers have been interpreted by considering how these materials are viscoelastic with low mechanical strength. However, preparing unvulcanized rubber nanocomposite reinforced by graphene oxide (GO) might provide insight into the investigation of GO effect on the cross-linking of GO/NBR nanocomposite before the vulcanization treatment. Also, the required property depends on how the rubber system responds to the deformations during the applied stresses and their rheological characteristics [2]. Therefore, improving the elastomer composites properties is a continuous effort, which would enable us to find high performance rubbers in addition to reducing the weight of the compounds and as well as the cost [3]. 
Carbon black (CB) and silica are still the main fillers for natural and synthetic rubber composites especially in the tires and some automobile parts industry [4]. Recently, reinforcement by nanoparticles has attracted much interest in the manufacturing of rubber nanocomposites due to the desirable nanofiller properties. This includes the large surface area of fillers which enables it to achieve improved mechanical and thermal properties even at low content of the nanofiller [5]. Currently, GO has grabbed substantial attention and interest from researchers to use this promising material for the preparation of graphene-based polymer nanocomposites. It is effective as a reinforcing nanofiller and is compatible with the polymers [6]. Similar to graphene, GO is fundamentally one-atom thicker but can be less than 50 micrometers, resulting in a unique type of building block material [7].

It is worth mentioning that $\mathrm{GO}$ has comparable mechanical properties with Carbon Nanotubes (CNT) $[5,8,9]$. Also, it has considerable thermal properties due to the surface area which theoretically is about $2600 \mathrm{~m}^{2} / \mathrm{g}$ compared to $1315 \mathrm{~m}^{2} / \mathrm{g}$ for CNT $[6,7,10]$. Therefore, the interface of GO layers when dispersed in the rubber matrix plays an effective role in reformatting the structure of rubber nanocomposites and changing its properties [11]. The improvement of mechanical properties of $\mathrm{GO} /$ polymer composites can be attributed to its high elastic modulus and stress transfer through the polymer matrices to GO sheets. The enhancement of rubber nanocomposite essentially depends on the degree of filler dispersion and interfacial adhesion with the elastomeric matrix [12]. Thus, the covalent and noncovalent adaptation of GO sheets in surface functionalization methods are an effective technique to improve the interfacial interactions between the sheets and rubber matrix [13].

The major methods of preparing nanocomposite polymers are direct mixing, in situ polymerization, and solution mixing method. Direct mixing involves mixing the nanofiller directly into the polymer using two roll mill mixer or internal polydrive thermal mixer. Even though this technique is safe, it may potentially lead to some aggregation of the nanofiller in the composite $[7,11]$. For in situ polymerization method, the filler is mixed with the monomer and essential reagents to activate the polymerization reaction in the presence or absence of a solvent. During the polymerization reaction, dispersion of the filler in the matrix can be obtained homogenously. This will lead to a greater reinforcement effect through the strong interfacial bonds formed. However, this method is not easy to perform due to the difficulty encountered in controlling the chemical process [9]. Solution mixing method is used for dispersing GO into different polymeric matrices such as thermoplastics, thermosets, and elastomers $[6,11]$. In this method, the process is performed by mixing GO suspension with the rubber solutions such as latex or dissolving of dry rubber in a compatible solvent using stirring and shear mixing [15]. Also, solution mixing method is the easiest and an effective method to disperse the graphene sheets in the rubber matrix compared to the other techniques [16].
Bai et al. [13] reported that nanosheets of GO were well mixed with hydrogenated carboxylated NBR for preparing HXNBR composite by solution mixing method. The results indicated that $\mathrm{GO}$ efficiently reinforced the tensile strength of the rubber due to the good interfacial interaction between the functional groups of the nanosheets and the carboxyl groups present in the HXNBR. In another research performed by $\mathrm{Li}$ et al. [17], GO/NBR nanocomposite was prepared by solution mixing method with various contents of GO. It was found that the frictional coefficient and specific wear rate of the nanocomposite increased with increasing GO loading. Also, Mensah et al. [18] used the solution mixing technique for preparing GO/NBR nanocomposite, whereby important results of curing and cross-linking density were obtained. Currently, researchers have not found a specific method which provides the same level of filler dispersion as solution mixing or in situ polymerization techniques [19]. In a different work, the high mechanical properties and low gas permeability of the GO/XNBR nanocomposite were associated with the homogeneous dispersion of the GO sheets which facilitated the load transfer from the rubber to the GO sheets [20].

The aim of this study was to homogeneously disperse GO sheets into dry NBR with low agglomeration using solvent mixing method. The optimization of the compatibility and suitability of the solvents for both filler and matrix were the most important objective of the work. The solution mixing method was selected as it is an effective technique, where the rubber solution has to be of low viscosity (latex-like) to disperse the GO sheets easily into the NBR matrix. Various characterization and properties tests were performed to study the influence of GO on the rubber nanocomposite structure without vulcanization.

\section{Experimental}

2.1. Materials. NBR Krynac-3345f (mooney viscosity ML $(1+4), 100^{\circ} \mathrm{C} 45 \pm 5 \mathrm{MU}$, and acrylonitrile content $33 \pm$ $1.0 \mathrm{wt} \%)$ was obtained from the Malaysian Rubber Board. Acetonitrile, chloroform, hexane, toluene, and acetone were purchased from R\&M Chemical Marketing (Ever Green Ltd.). GO sheets $\left(1.12 \mathrm{~g} / \mathrm{cm}^{3}\right.$ density) were prepared by using modified Hummer's method described elsewhere [21, 22].

2.2. Preparation of NBR and GO Solutions. The following steps explain the determination of the suitable NBR solvent and compatibility of GO suspension before proceeding to prepare GO/NBR nanocomposite.

Step 1. In order to find a suitable solvent, NBR was cut into smaller fragments. Then five samples of $2.5 \mathrm{~g}$ NBR each were dissolved in $100 \mathrm{~mL}$ of 5 different organic solvents: chloroform, hexane, toluene, acetone, and acetonitrile. A magnetic stirrer (IKA C-MAG HS7) was used with normal speed to dissolve NBR completely at a constant temperature of $70^{\circ} \mathrm{C}$ for all samples and the dissolving time was measured. Then, the viscosity measurement was carried out by Brookfield DVI+ Viscometer according to ISO 2555. 
Step 2. Meanwhile, to find the compatible solvent for GO, three types of solvents, DMF, hydrogen peroxide $\left(\mathrm{H}_{2} \mathrm{O}_{2}\right)$, and distilled water $\left(\mathrm{H}_{2} \mathrm{O}\right)$ in addition to the rubber solvent, were used to disperse GO. $10 \mathrm{mg}$ of GO was dispersed in $25 \mathrm{~mL}$ of each of the mentioned solvents in flasks using ultrasonication (Sonics-VCX750) at $20^{\circ} \mathrm{C}$. The sonication process was carried out under mild condition of power and frequency. The GO in these solvents showed different appearances as shown and discussed in Section 3.1.

Step 3. Investigation of the hydrophilicity was conducted to gain more confirmation regarding the homogeneity and compatibility between the rubber solvents and $\mathrm{GO} / \mathrm{H}_{2} \mathrm{O}$ solution. For that, five glass tubes were filled with $15 \mathrm{~mL}$ of each respective solvent which was mentioned above. Another $15 \mathrm{~mL}$ of the sonicated $\mathrm{GO} / \mathrm{H}_{2} \mathrm{O}$ suspension was added to each glass tube. The mixtures were sonicated and the final samples were observed, where the best solvent was the one which produced a homogeneous suspension.

2.3. Preparation of GO/NBR Nanocomposite. The unvulcanized GO/NBR nanocomposite was prepared by following the chemical and physical approaches as illustrated in Figure 1. Mechanical mixing was performed by adding different loading $(0.2,0.4,0.8$, and $1 \mathrm{wt} \%)$ of GO in suspension solutions into NBR solution (10 g rubber $/ 500 \mathrm{~mL}$ solvent) with a speed range of 200-1000 rpm for two hours. For each sample, the nanocomposite rubber mixture coagulated, where the water quantity in GO solution and the time of the mixture were qualitatively monitored. Then, the nanocomposite mixture was dried in a vacuum oven at $70^{\circ} \mathrm{C}$ and $0.07 \mathrm{MPa}$ vacuum pressures for around 18 hours until there was no change in the weight. The dried sample of GO/NBR nanocomposite was masticated by an internal mixer (Haake PolyDrive R600) at $35^{\circ} \mathrm{C}$ temperature. Subsequently, $8 \mathrm{~g}$ of the mixture was precast by a die plate with dimensions of $(8 \times 8 \times 0.1) \mathrm{cm}$. Two hot plates of pressing machine (Lab Tech Eng. Co. Ltd.) were used based on the (ASTM D3182) at 120,130 , and $160^{\circ} \mathrm{C}$, under hydraulic compression of $5 \mathrm{MPa}$. Optimum times of preheating and pressing with heating followed by cooling were carried out. Finally, flat sheets of unvulcanized GO/NBR nanocomposite samples containing various contents of GO were prepared.

2.4. Characterization of GO/NBR Nanocomposites. The morphology of GO, NBR, and unvulcanized GO/NBR nanocomposite samples was studied. The microstructure surfaces of the samples were characterized by Scanning Electron Microscope (SEM) (Hitachi-S-3400N). Fourier-Transform Infrared Spectroscopy (FTIR) was carried out to characterize GO, NBR, and unvulcanized GO/NBR nanocomposites. This test was performed by using (Nicolet 6700) spectrometer over a wavenumber range of $400-4000 \mathrm{~cm}^{-1}$. Dispersion of GO into NBR was further characterized by X-Ray Diffractometer (XRD) (Shimadzu 6000) with monochromatic Cu K-alpha, scan range of 2-60, and scan speed of $2 \mathrm{deg} . / \mathrm{min}$. XRD was used to identify the intercalated structures of the GO sheets layers in NBR matrix for both of the pristine and the intercalated composites and for analyzing the dispersion degree of GO sheets.

2.5. Properties of GO/NBR Nanocomposites. The tensile strength of unvulcanized GO/NBR nanocomposites samples was examined by using an Instron machine (5566 10 KN) according to ASTM D412 [23], standard which was controlled by a Blue Hill software system. The influence of GO dispersion into the NBR matrix was studied through the stress-strain curves. The related parameters such as modulus and elongation were described, in addition to the yield and breakpoints based on GO content wt\% in NBR.

The electrical conductivity was tested by calculating the electrical resistant $(R)$ using Ohm's law $(R=V / I)$. The electrical current $(I)$ was detected by a multimeter (Keithley2000). A digital voltmeter for measuring the voltage $(V)$ was connected to two cylindrical copper electrodes, as shown in Figure 2. Complete contact between the electrodes and the sample's surface was achieved by placing the samples between them. The unvulcanized GO/NBR nanocomposites samples having different GO loadings with dimensions of $1 \times 1 \times$ $0.1 \mathrm{~cm}$ were tested. The electrical conductivity was calculated.

\section{Results and Discussion}

3.1. Compatibility and Suitability of NBR and GO Solutions. Table 1 shows dissolution time, viscosity, and appearance of NBR in different solvents. It can be seen that the NBR solutions exhibited different properties and appearance when dissolved in different solvents. This might be attributed to the molecular weight and the polarity of the solvents which affected the rubber viscoelastic properties.

The results showed that NBR dissolved in acetone and acetonitrile have lower viscosity when compared to the others. Acetone was the preferred solvent because its lower boiling point $\left(56.2^{\circ} \mathrm{C}\right)$ compared to acetonitrile $\left(81.6^{\circ} \mathrm{C}\right)[23$, $24]$ is more suitable for solution mixing process. Furthermore, acetone has a lower impact on the environment as well as lower cost.

The dispersion of GO sheets in different solvents was observed and recorded in Table 2. The GO sheets were seen to agglomerate slightly in DMF and acetone, unlike the full dispersion achieved with $\mathrm{H}_{2} \mathrm{O}_{2}$ and $\mathrm{H}_{2} \mathrm{O}$. Based on these observations, water was chosen as the most compatible solvent for GO dispersion. The aqueous media play a significant role to ensure homogeneous dispersion of GO and compatibility with the dissolved NBR solution.

Figure 3 shows the appearance of $\mathrm{GO} / \mathrm{H}_{2} \mathrm{O}$ suspensions when mixed with different solvents. It can be seen that $\mathrm{GO} / \mathrm{H}_{2} \mathrm{O}$ suspension mixed relatively well with the acetone and acetonitrile compared to the other solvents as shown in Figure 3(a). Despite being relatively good solvents for NBR, hexane and toluene are both hydrophobic organic solvents and their densities are lower than water, so they separated to form a top layer. Similarly, chloroform separated to the bottom layer due to its higher density. After one month the segregation of GO sheets was obvious in hexane, toluene, and chloroform as shown in Figure 3(b). 


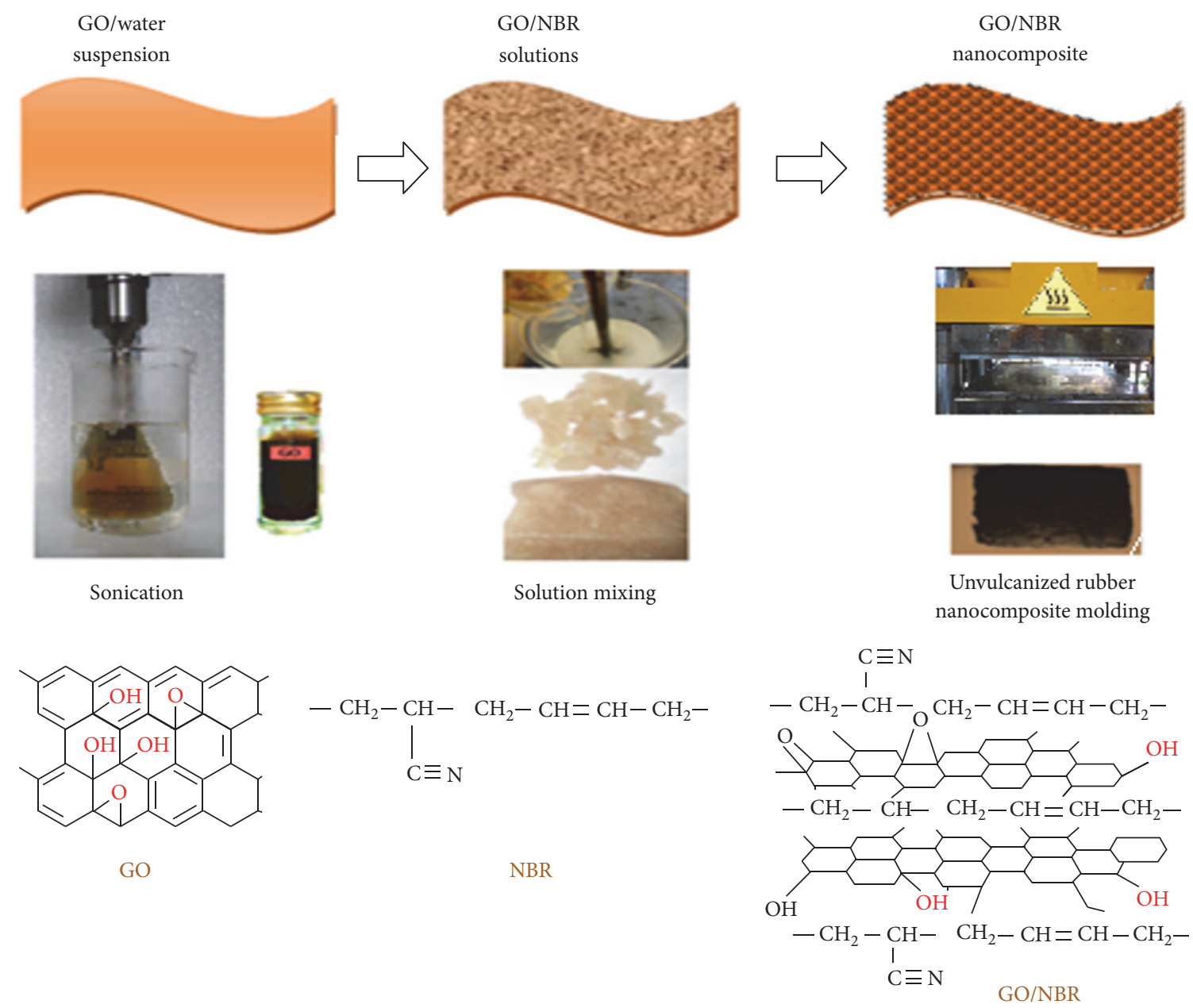

FIGURE 1: The preparation stages of unvulcanized GO/NBR nanocomposite.

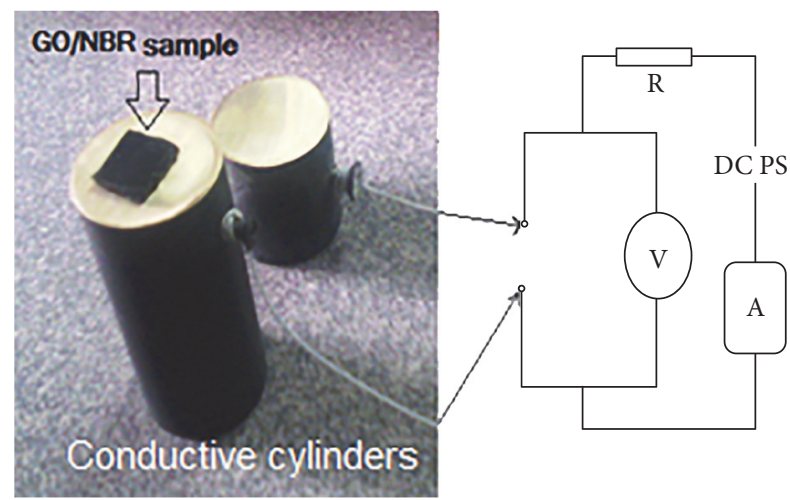

Figure 2: The electrical resistance test of the unvulcanized GO/NBR nanocomposite using two cylindrical copper electrodes.

These observations showed that acetone and acetonitrile in Figures 3(a)(D) and 3(a)(E) appeared to be good solvents for preparing GO/NBR nanocomposites by solution mixing. However, although acetonitrile has good characteristics for preparing nanocomposite rubber with high recycling quantity of solvent after the rubber mixture coagulation as well as before drying, it is not a good solvent to handle healthwise. Based on these considerations, acetone was chosen as the most suitable solvent for preparing GO/NBR nanocomposite in an aqueous environment.

3.2. Dispersion of GO into NBR. The coagulation state of the GO/NBR mixture was found to be affected by the aqueous medium. As shown in Table 3, the amount of water in the GO suspension influences the time of rubber coagulation. The observed trend is also shown in Figure 4. The GO dispersion was incomplete when the volume of water was $10 \mathrm{~mL}$, where obvious agglomeration in the final mixture appeared. Early coagulation was avoided by using a low volume of water $2 \mathrm{~mL}$, whereby the coagulation time was increased to $55 \mathrm{~min}$. Avoiding early coagulation as well as keeping a low solution viscosity around $140 \mathrm{c}$ poise is highly desirable as this would allow sufficient time for the GO sheets to be dispersed well in the NBR solution with minimal agglomeration. It is worth mentioning that the ultrasonication technique was not used for mixing the nanocomposite, whereby the sonication process can result in chain scission and a decrease in molecular weight of the polymers $[22,23,25]$. 
TABLE 1: Dissolution time, viscosity, and appearance of NBR in various solvents.

\begin{tabular}{lcccc}
\hline $\begin{array}{l}\text { Organic } \\
\text { solvents }\end{array}$ & MW of the solvents & Dissolving time (min) & $\begin{array}{c}\text { Viscosity } \\
(\text { c poise })^{* *}\end{array}$ & $\begin{array}{c}\text { Color and T if it is } \\
\text { transparent }\end{array}$ \\
\hline Acetonitrile & 41.05 & 60 & 132 & Light beige, T \\
Acetone & 58.08 & 50 & 140 & Pale pink \\
Hexane & 86.18 & 280 & 163 & Light yellow \\
Toluene & 92.14 & 360 & 167 & Light brown \\
Chloroform & 119.4 & 150 & 178 & Beige, T \\
\hline
\end{tabular}

Rubber concentration $=2.5 \mathrm{~g} \mathrm{NBR} / 100 \mathrm{~mL}$ solvent, Brookfield-DV-I+ Viscometer with spindle type $=s 63,10 \mathrm{RPM}$, and Torque $=1.3 \mathrm{dm} \cdot \mathrm{N} \pm 0.1$.

${ }^{*}$ Molecular weights of common organic solvents created by Professor Murov's Orgsoltab, edited by Murov's [14].

${ }^{* *} 1 \mathrm{cP}($ poise $)=1 \mathrm{~m} \cdot \mathrm{Pa} \cdot \mathrm{s}$.

TABLE 2: Appearance of GO dispersion in different solvents.

\begin{tabular}{l|lll}
\hline $\begin{array}{l}\text { Sonication } \\
\text { conditions }\end{array}$ & DMF & \multicolumn{2}{c}{ Appearance (GO dispersion) } \\
\hline $300 \mathrm{watt}$ & & \\
$20 \mathrm{kHz}$. & & \\
$30^{\circ} \mathrm{C}$ \\
$30 \mathrm{~min})$ \\
$10 \mathrm{mg} / 25 \mathrm{~mL}$
\end{tabular}
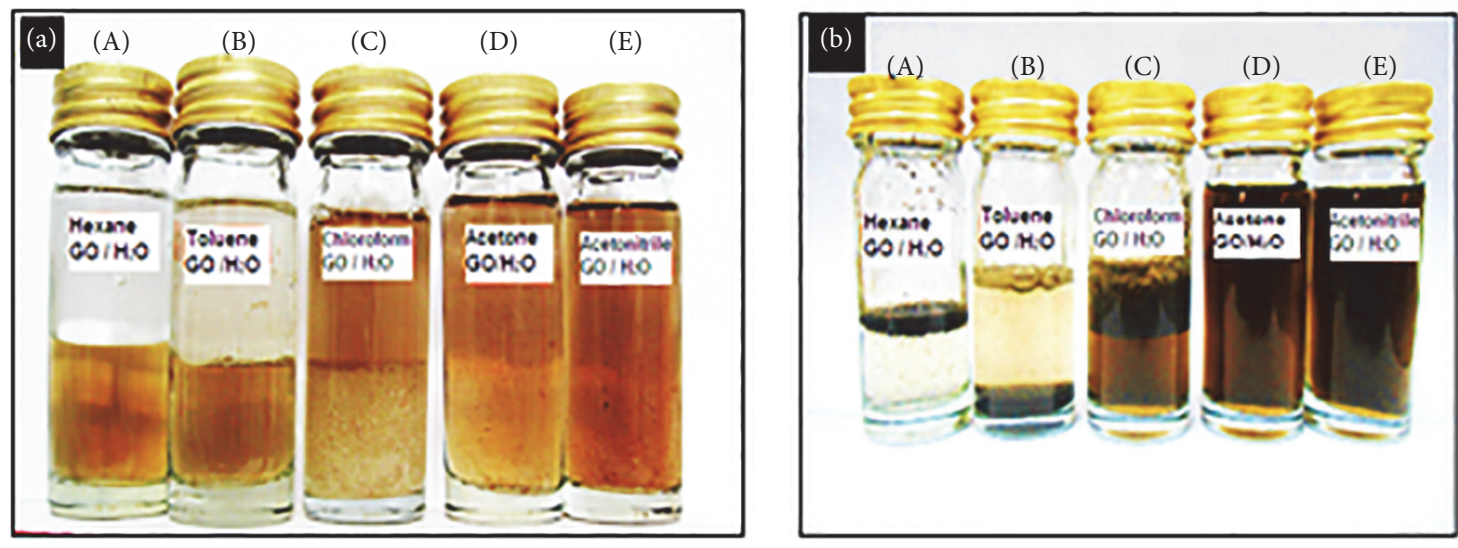

Figure 3: (a) Five different organic solvents mixed with $\mathrm{GO} / \mathrm{H}_{2} \mathrm{O}$ suspension: (A) hexane, (B) toluene, (C) chloroform, (D) acetone, and (E) acetonitrile. (b) The same samples after one month.

The morphology of the GO, NBR, and GO/NBR nanocomposite was observed by SEM and shown in Figure 5. The SEM micrograph of the GO surface in Figure 5(a) showed multilayers of graphene sheets. It was difficult to distinguish the layer features due to the overlapping of GO sheets. The nature of the NBR surface appeared as one phase as shown in Figure 5(b). When the rubber nanocomposite GO/NBR was reinforced by $1 \mathrm{wt} \%$ of GO using direct mixing method, the surface showed considerable aggregation of GO sheets as shown in Figure 5(c). However, by using the solution mixing method followed by an internal mixer (polydrive), GO sheets appeared to be dispersed well with minimal appearance of agglomeration as shown in Figure 5(d). This might be due to the improved interfacial interaction between GO sheets and the matrix of NBR $[15,21]$.

The FTIR spectra of GO, NBR, and GO/NBR nanocomposites are shown in Figure 6. The broad peak of GO at around $3250 \mathrm{~cm}^{-1}$ is assigned to the hydroxyl group $\mathrm{O}-\mathrm{H}$ 
TABLE 3: Effect of water volume in the GO suspension on the coagulation time of the GO/NBR nanocomposite.

\begin{tabular}{|c|c|c|c|}
\hline $\begin{array}{l}\begin{array}{l}\text { Distilled } \\
\text { water volume } \\
(\mathrm{mL})\end{array} \\
\end{array}$ & $\begin{array}{l}\text { Coagulation } \\
\text { time (min) }\end{array}$ & $\begin{array}{c}\mathrm{GO} \\
\text { dispersion }\end{array}$ & $\begin{array}{c}\text { Coagulation } \\
\text { state of } \\
\text { GO/NBR }\end{array}$ \\
\hline 10 & 0.5 & Incomplete & Coagulated \\
\hline 8 & 1 & Incomplete & $\begin{array}{c}\text { Coagulated, } \\
\text { melted }\end{array}$ \\
\hline 6 & 15 & Partially & $\begin{array}{c}\text { Viscos, } \\
\text { coagulated }\end{array}$ \\
\hline 4 & 35 & Complete & $\begin{array}{l}\text { Viscos } \\
\text { solution }\end{array}$ \\
\hline 2 & 55 & Max. disp & $\begin{array}{l}\text { Low viscous } \\
\text { solution }\end{array}$ \\
\hline
\end{tabular}

and recognized as a stretching vibration. The spectrum of unfilled NBR showed the main peaks at $2900 \mathrm{~cm}^{-1}$ associated with $-\mathrm{CH}_{2}$ - bonds. Most peaks of unfilled NBR were the same as the unvulcanized GO/NBR nanocomposite in their FTIR spectra. At wave number $2230 \mathrm{~cm}^{-1}, \mathrm{C}=\mathrm{O}$ of carboxylic acid was recognized and $\mathrm{C}=\mathrm{C}$ from unoxidized GO surface at $1950 \mathrm{~cm}^{1} . \mathrm{C}=\mathrm{O}$ of the carboxyl group in the GO/NBR nanocomposite containing $1 \mathrm{wt} \%$ of GO appeared at $2100 \mathrm{~cm}^{-1}$. This is due to the formation of $-\mathrm{H}$ bonding between the carboxylic group $(-\mathrm{COOH})$ of NBR and hydroxyl groups $(-\mathrm{OH})$ of the $\mathrm{GO}$ sheets. However, the peaks that appear around $1400-1800 \mathrm{~cm}^{-1}$ represent the carbonyl stretching. Also, the peaks due to $\mathrm{CH}_{2}$ deformation at 1452, 1397 , and $1262 \mathrm{~cm}^{-1}$ have been lowered in the composite. These groups have an important role in the crosslink enhancement. It can be seen that the butadiene stretch peaks at $969 \mathrm{~cm}^{-1}$ have become sharper and intense. This might be due to the interaction of butadiene double bond with the $\pi$ electrons of graphene. The essential characteristics were the same at the same wave numbers for both NBR and GO/NBR due to the GO existence. Moreover, the acrylonitrile NBR molecules chains are linked with the carbon atoms of GO through the free-radical initiators. Nonetheless, the functional groups including oxygen around GO sheets surfaces have increased the contribution strongly with the rubber nitrile monomers. This interfacial interaction enhanced and improved the adhesion between GO and NBR matrix and the mechanical properties [21, 26].

Dispersion of GO sheets into NBR was further characterized by XRD as shown in Figure 7. It shows the diffraction pattern of GO, unfilled NBR, and unvulcanized GO/NBR nanocomposites with various GO loading. The typical diffraction peak of GO was observed at $2 \theta=11.39^{\circ}$. Also, the interlayer space (d) was $0.77 \mathrm{~nm}$ which is larger than that of graphite platelets due to the oxidizing process $[17,18]$. The characteristic broad peak of NBR was found at $2 \theta$ $=20^{\circ}$ which is the same as the nanocomposites of GO/NBR. It may indicate that GO sheets have been dispersed completely where, due to the noncrystalline structure of the polymer, a broad diffraction peak is detected in the NBR curve. However, the XRD pattern of the GO/NBR nanocomposites containing $0.2,0.4$, and $0.8 \mathrm{wt} \% \mathrm{GO}$ shows wide diffraction peaks similar to that of unfilled NBR. This indicates that the periodic crystalline structure of GO vanished in the rubber and GO was fully exfoliated into monolayer or few layers in NBR matrix [26] where the exfoliation depends on the processing technique and affinity between the sheets. The percolation load of GO in NBR shows up via the reduction in the intensity of X-ray at $1 \mathrm{wt} \%$ of GO in the rubber composite. This result was verified by comparing with other studies reported $[9,18$, 21].

3.3. Physical Properties of GO/NBR Nanocomposite. Table 4 shows the tensile properties of GO/NBR nanocomposites at different GO loadings. The stress-strain curves shown in Figure 8(a) provide insight about the influence of GO on the tensile strength, modulus, and tensile strain of the unvulcanized rubber nanocomposites. There were evident increases in stress values along with the increase in GO loading in the nanocomposites. Figure 9 shows the influence of increasing GO loading on stress and modulus improving at maximum load. This proportional relationship was due to the reinforcement by the intercalation of GO sheets in the rubber matrix whereby the improvement is attributed to the restriction in the rubber chain mobility due to the GO sheet presence. Moreover, the functional groups such as oxygen and carboxyl around GO surfaces have the main role in enhancing the cross-linking of the composites structure. Also, the decrease in tensile extension at maximum load was due to the increase in GO loading. However, some fluctuated data might be due to either the preparation process or the rubber characteristics. The modulus at the elastic region and other results were shown in Table 5 .

In addition, the graph in Figure 8(b) shows the linear behavior at the initial elastic region of the stress-strain curves of Figure 8(a). It can be seen that Young's modulus increases as GO loading increases. The increment was about $238 \%$ at 0.8 and $1 \mathrm{wt} \%$ of GO compared to the unfilled NBR. At 0.2 and $0.4 \mathrm{wt} \%$ content of GO, there was no significant change in the elasticity in this range of loading due to the less deformation which might be involved. However, they have more than $100 \%$ increment in the modulus from that of the unfilled NBR, with the same resiliency property. Unfilled NBR showed a high value of the extension due to the free mobility of the 


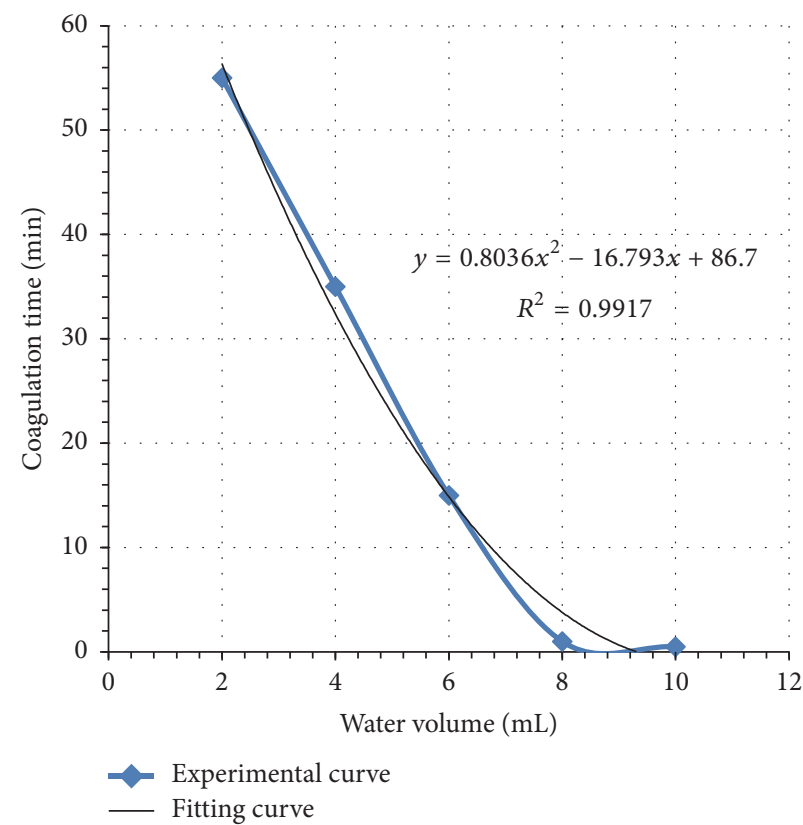

FIgURE 4: The relationship between water content in the GO/NBR nanocomposite solution and the coagulation time (min).
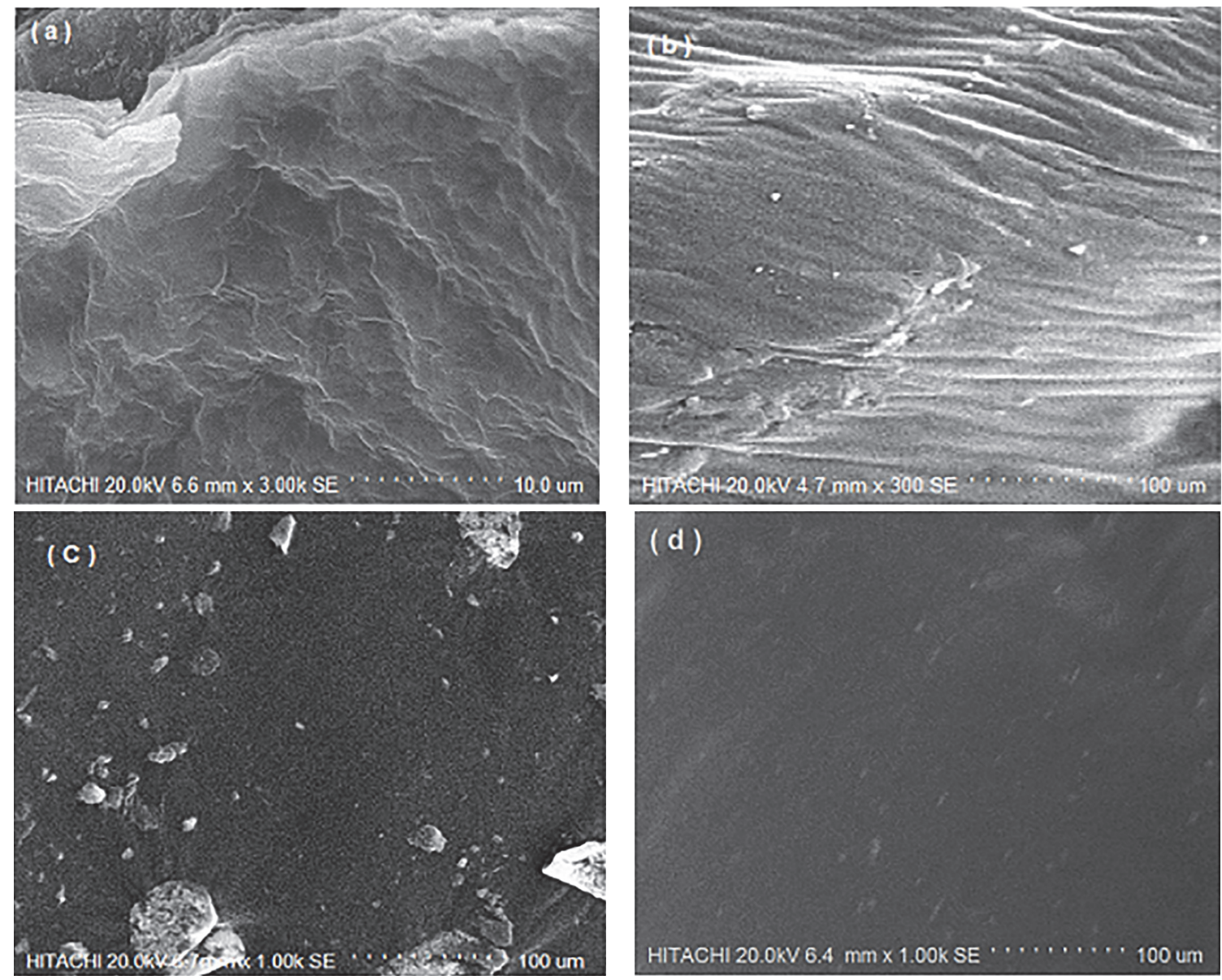

FIGURE 5: SEM micrographs of (a) GO, (b) NBR, (c) GO/NBR mixed by direct mixing method, and (d) GO/NBR mixed by solution mixing and internal mixer. 


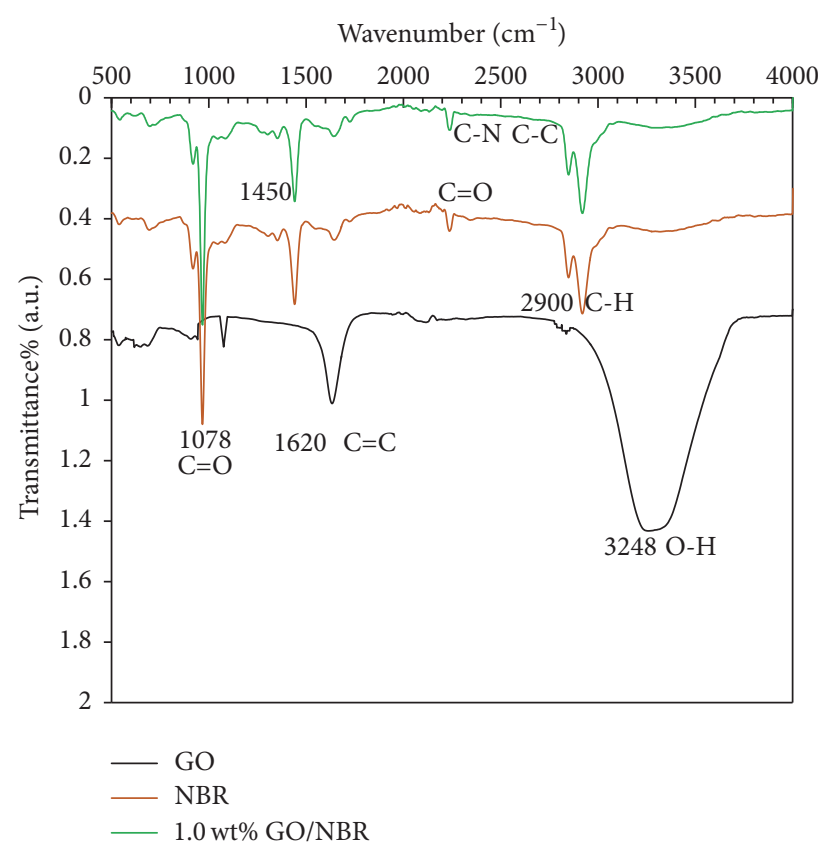

FIGURE 6: FTIR of GO, NBR, and unvulcanized GO/NBR nanocomposite with 1 wt $\%$ of GO.

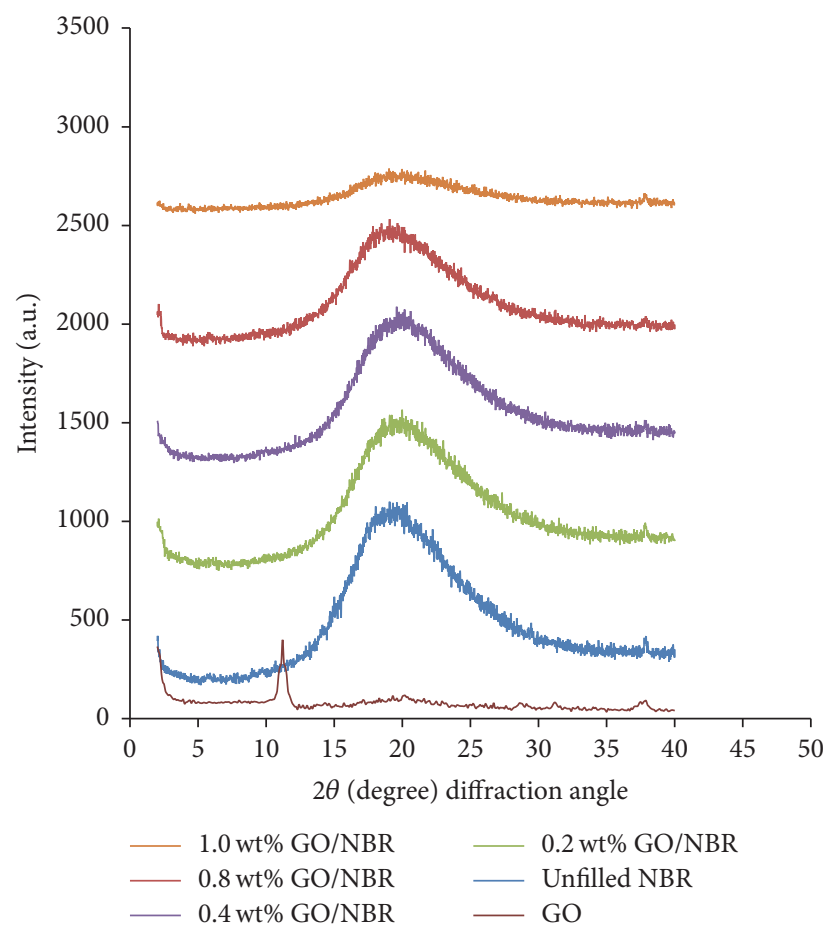

FIGURE 7: XRD plots of GO, NBR, and several of unvulcanized GO/NBR nanocomposites.

elastomer chains, so the percentage of strain increased. This result was compatible with other reported results [17, 18, 27] Furthermore, GO influence on rubber nanocomposite as shown in Figure 9 was noticeable on the stress and modulus at maximum load as GO loading increased. Those tests were significant in verifying the homogeneity of GO dispersion in the rubber matrix.
Table 5 shows the electrical conductivity of unvulcanized GO/NBR nanocomposites at different GO loadings. The generally low electrical conductivity in the unvulcanized rubber nanocomposites of $\mathrm{GO} / \mathrm{NBR}$ is most probably due to the high electrical resistance of NBR and GO. This might be attributed to the nitrile content and the polarity of NBR which affect the dielectric loss $\varepsilon$ as reported in [26]. However, the 
TABLE 4: Tensile properties of unvulcanized GO/NBR nanocomposites at different GO loadings.

\begin{tabular}{lcccc}
\hline $\begin{array}{l}\text { GO loading } \\
\text { wt\% }(\mathrm{g})\end{array}$ & $\begin{array}{c}\text { Tensile stress } \\
\text { at max. load } \\
(\mathrm{MPa})\end{array}$ & $\begin{array}{c}\text { Tensile strain } \\
\text { at max. load } \\
\%\end{array}$ & $\begin{array}{c}\text { Modulus at } \\
\text { max. load } \\
(\mathrm{MPa})\end{array}$ & $\begin{array}{c}\text { Tensile } \\
\text { extension at } \\
\text { max. load } \\
(\mathrm{mm})\end{array}$ \\
\hline 0.0 & 0.32 & 1088.66 & 0.342 & 435.46 \\
0.2 & 476.58 & 0.223 & 190.63 \\
elastic region \\
$(\mathrm{MPa})$
\end{tabular}



(a)

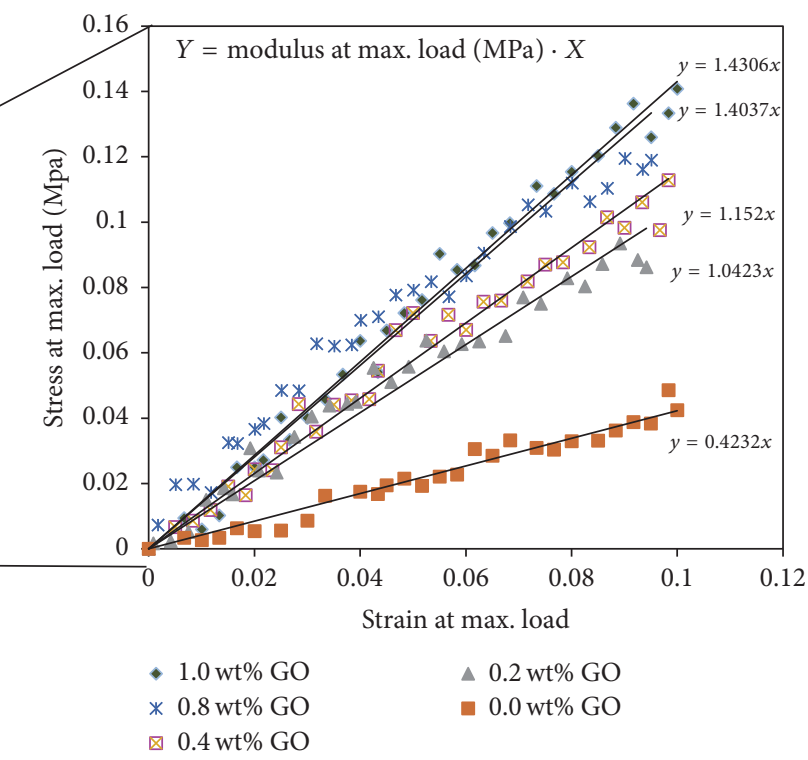

(b)

FIGURE 8: Stress-strain curves of NBR and unvulcanized GO/NBR nanocomposites at different GO loadings for (a) all the test and (b) the linear elastic region.

data shows that as the GO loading is increased the electrical current through the unvulcanized GO/NBR nanocomposites also increased but slightly. As a result, the electrical resistivity decreased as GO loading increased, where the maximum value of the electrical current reached $2 \mathrm{nA}$ (nanoamperes). This was attributed to the fact that a path may have been created through the GO sheets for the electrical charges to flow through the GO/NBR nanocomposite. It was noted that the data for $0.2 \mathrm{wt} \%$ content of GO was slightly off trend, whereby the current reduced to $0.76 \mathrm{nA}$ from $0.98 \mathrm{nA}$ for unfilled NBR. It may be attributed to the effects of the NBR molecules polarization and constraining the free electrostatic charges movement which existed on the few sheets of GO. When the sample of $0.2 \mathrm{wt} \% \mathrm{GO}$ in GO/NBR composite was placed between the two conductors shown previously in Figure 2, the external electrical field polarized the composite molecules. Another electrical filed was created by the dipoles which were moved against the main field, so low electrical current was passed through the rubber composite. This phenomenon is ascribed to various influencing factors such as the electrical characteristics of GO. Moreover, quality of GO exfoliation and dispersion, used solvents, mixing technique, and the molecular weight of the compounds all have essential effects too [27].

Despite the generally low electrical conductivity of unvulcanized GO/NBR nanocomposites, the results provide some indication that good dispersion was achieved. This is because the effective dispersion of GO allows the creation of GO networks with some conducting pathways throughout the NBR matrix. Note that the electrical conductivity of GO/NBR nanocomposite can be improved by reducing graphene oxide (RGO) partially, which is necessary to remove functional groups which block the electrical conductivity $[9,18]$.

\section{Conclusions}

Successful dispersion of GO sheets into NBR was achieved by using a suitable solution mixing method which involved finding compatible solvents for both NBR and GO suspensions. Amongst the organic solvents, acetone was the most suitable to dissolve NBR and created a well-dispersed GO/NBR mixture. Furthermore, full-drying and consistent mastication 


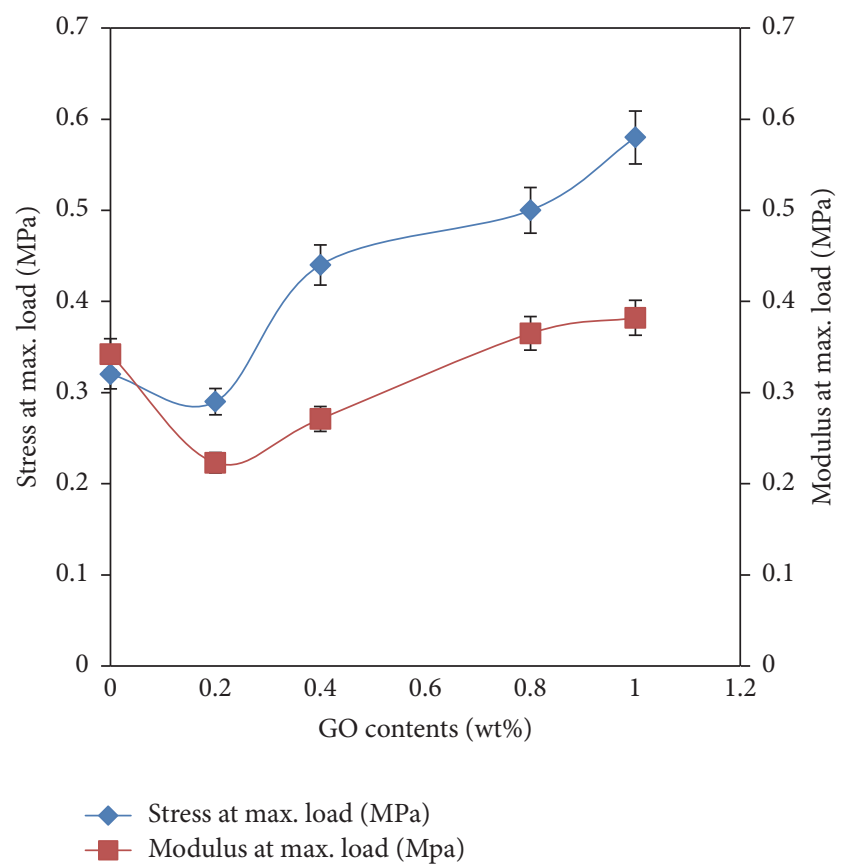

Figure 9: Effect of GO content in unvulcanized GO/NBR nanocomposite on their stress and modulus at max. load ( $\mathrm{MPa})$.

TABLE 5: The electrical conductivity of unvulcanized GO/NBR nanocomposites at different GO loadings.

\begin{tabular}{lccc}
\hline $\begin{array}{l}\text { GO loading } \\
\text { wt\% }(\mathrm{g})\end{array}$ & $\begin{array}{c}\text { Current } \\
I \times 10^{-9}(\mathrm{~A})\end{array}$ & $\begin{array}{c}\text { Resistivity } \\
\rho \times 10^{9} \\
(\Omega \cdot \mathrm{cm})\end{array}$ & $\begin{array}{c}\text { Conductivity } \\
(\mathrm{S} / \mathrm{cm})\end{array}$ \\
\hline 0.0 & 0.98 & 39.15 & 25.54 \\
0.2 & 0.76 & 50.51 & 19.80 \\
0.4 & 1.46 & 26.29 & 38.03 \\
0.8 & 1.88 & 20.43 & 48.94 \\
1.0 & 1.93 & 19.91 & 50.22 \\
\hline
\end{tabular}

assisted the homogeneity of GO dispersion into the NBR matrix with minimal agglomeration, which was supported by SEM and XRD analysis. The tensile strength was improved and the modulus of unvulcanized GO/NBR nanocomposites was increased by about $238 \%$ at $1 \mathrm{wt} \%$ content of GO in the composite compared with unfilled NBR. Also the elongation and tensile strain were decreased to about $50 \%$. This is an indication that the cross-linking between GO sheets and NBR chains was formed without vulcanization but for specific purposes. Electrical conductivity measurements indicated the low increase in the conductivity of the unvulcanized GO/NBR with increasing GO loading. This study provides insight into the dispersion of GO into NBR matrix and characteristics of unvulcanized nanocomposite for coatings or adhesive application.

\section{Competing Interests}

The authors declare no conflict of interests.

\section{Acknowledgments}

The authors acknowledge the financial support from various grants under the Institute of Advanced Technology (ITMA), University Putra Malaysia. The authors also acknowledge personnel from the Malaysian Rubber Board, Engineer Kamarul Arifin (Physical Properties Laboratory) and Mr. Abdullah Juha (Rubber Processing Unit) for valuable consultations.

\section{References}

[1] F. W. Barlow, Rubber Compounding; Principles, Materials, and Techniques, Marcel Dekker, New York, NY, USA, 2nd edition, 1993.

[2] J. L. White, "Rheological behavior and processing of unvulcanized rubber," in Science and Technology of Rubber, pp. 237-284, Elsevier, Dayton, Ohio, USA, 3rd edition, 2005.

[3] P. M. Visakh, S. Thomas, A. K. Chandra, and A. P. Mathew, Advances in Elastomers II-Composites and Nanocomposites, vol. 12, Springer, Berlin, Germany, 1st edition, 2013.

[4] D. Frasca, D. Schulze, V. Wachtendorf, B. Krafft, T. Rybak, and B. Schartel, "Multilayer graphene/carbon black/chlorine isobutyl isoprene rubber nanocomposites," Polymers, vol. 8, no. 3, article 95, 2016.

[5] L. Bokobza, "Multiwall carbon nanotube elastomeric composites: a review," Polymer, vol. 48, no. 17, pp. 4907-4920, 2007.

[6] M. M. Gudarzi and F. Sharif, "Enhancement of dispersion and bonding of graphene-polymer through wet transfer of functionalized graphene oxide," Express Polymer Letters, vol. 6, no. 12, pp. 1017-1031, 2012.

[7] J. R. Potts, D. R. Dreyer, C. W. Bielawski, and R. S. Ruoff, "Graphene-based polymer nanocomposites," Polymer, vol. 52, no. 1, pp. 5-25, 2011.

[8] P. Visakh, T. Sabu, A. K. Chandra, and A. P. Mathew, Eds., Advances in Elastomers I: Blends and Interpenetrating Networks, vol. 11 of Advanced Structured Materials, Springer, Berlin, Germany, 2013.

[9] K. K. Sadasivuni, D. Ponnamma, S. Thomas, and Y. Grohens, "Evolution from graphite to graphene elastomer composites," Progress in Polymer Science, vol. 39, no. 4, pp. 749-780, 2014.

[10] A. Peigney, C. Laurent, E. Flahaut, R. R. Bacsa, and A. Rousset, "Specific surface area of carbon nanotubes and bundles of carbon nanotubes," Carbon, vol. 39, no. 4, pp. 507-514, 2001.

[11] T. V. Varghese, H. Ajith Kumar, S. Anitha, S. Ratheesh, R. S. Rajeev, and V. Lakshmana Rao, "Reinforcement of acrylonitrile butadiene rubber using pristine few layer graphene and its hybrid fillers," Carbon, vol. 61, pp. 476-486, 2013.

[12] D. Ponnamma, C. J. Chirayil, K. K. Sadasivuni, and L. Somasekharan, Advances in Elastomers I, vol. 11, 2013.

[13] X. Bai, C. Wan, Y. Zhang, and Y. Zhai, "Reinforcement of hydrogenated carboxylated nitrile-butadiene rubber with exfoliated graphene oxide," Carbon, vol. 49, no. 5, pp. 1608-1613, 2011.

[14] O. E. Murov's, "Common Organic Solvents: Table of Properties," vol. 5. ChemFinder Web Server, pp. 4-5, https://www .organicdivision.org/orig/organic_solvents.html.

[15] D. Dreyer and S. Park, "The chemistry of graphene oxide," Chemical Society Reviews, vol. 39, pp. 228-240, 2010.

[16] A. K. Bhowmick, M. Bhattacharya, S. Mitra et al., "Morphologyproperty relationship in rubber-based nanocomposites: some recent developments," in Advanced Rubber Composites, vol. 239, pp. 1-83, Springer, Berlin, Germany, 2010. 
[17] Y. Li, Q. Wang, T. Wang, and G. Pan, "Preparation and tribological properties of graphene oxide/nitrile rubber nanocomposites," Journal of Materials Science, vol. 47, no. 2, pp. 730-738, 2012.

[18] B. Mensah, S. Kim, S. Arepalli, and C. Nah, "A study of graphene oxide-reinforced rubber nanocomposite," Journal of Applied Polymer Science, vol. 131, no. 16, Article ID 40640, 9 pages, 2014.

[19] D. Galpaya, M. Wang, M. Liu, N. Motta, E. Waclawik, and C. Yan, "Recent advances in fabrication and characterization of graphene-polymer nanocomposites," Graphene, vol. 1, no. 2, pp. 30-49, 2012.

[20] V. Georgakilas, M. Otyepka, A. B. Bourlinos et al., "Functionalization of graphene: covalent and non-covalent approaches, derivatives and applications," Chemical Reviews, vol. 112, no. 11, pp. 6156-6214, 2012.

[21] H. Kang, K. Zuo, Z. Wang, L. Zhang, L. Liu, and B. Guo, "Using a green method to develop graphene oxide/elastomers nanocomposites with combination of high barrier and mechanical performance," Composites Science and Technology, vol. 92, pp. 1-8, 2014

[22] T. Rattana, S. Chaiyakun, N. Witit-Anun et al., "Preparation and characterization of graphene oxide nanosheets," Procedia Engineering, vol. 32, pp. 759-764, 2012.

[23] ASTM, "Standard test method for tensile properties of polymer matrix composite materials," Mechanical Testing Laboratory Index, vol. 15, no. 1, pp. 105-116, 2014.

[24] F. Tu, S. Liu, G. Jin, G. Yan, and C. Pan, "Fabrication of graphene from graphene oxide by ultrasonication with high Li storage capability," Powder Technology, vol. 249, pp. 146-150, 2013.

[25] Y. Li, R. Umer, Y. A. Samad, L. Zheng, and K. Liao, “The effect of the ultrasonication pre-treatment of graphene oxide (GO) on the mechanical properties of GO/polyvinyl alcohol composites," Carbon, vol. 55, pp. 321-327, 2013.

[26] U. Wiesner, "Advances rubber composites," in Advances in Polymer Science, G. Heinrich, Ed., pp. 25-37, Springer, Dresden, Germany, 2011.

[27] H. Pang, L. Xu, D.-X. Yan, and Z.-M. Li, "Conductive polymer composites with segregated structures," Progress in Polymer Science, vol. 39, no. 11, pp. 1908-1933, 2014. 

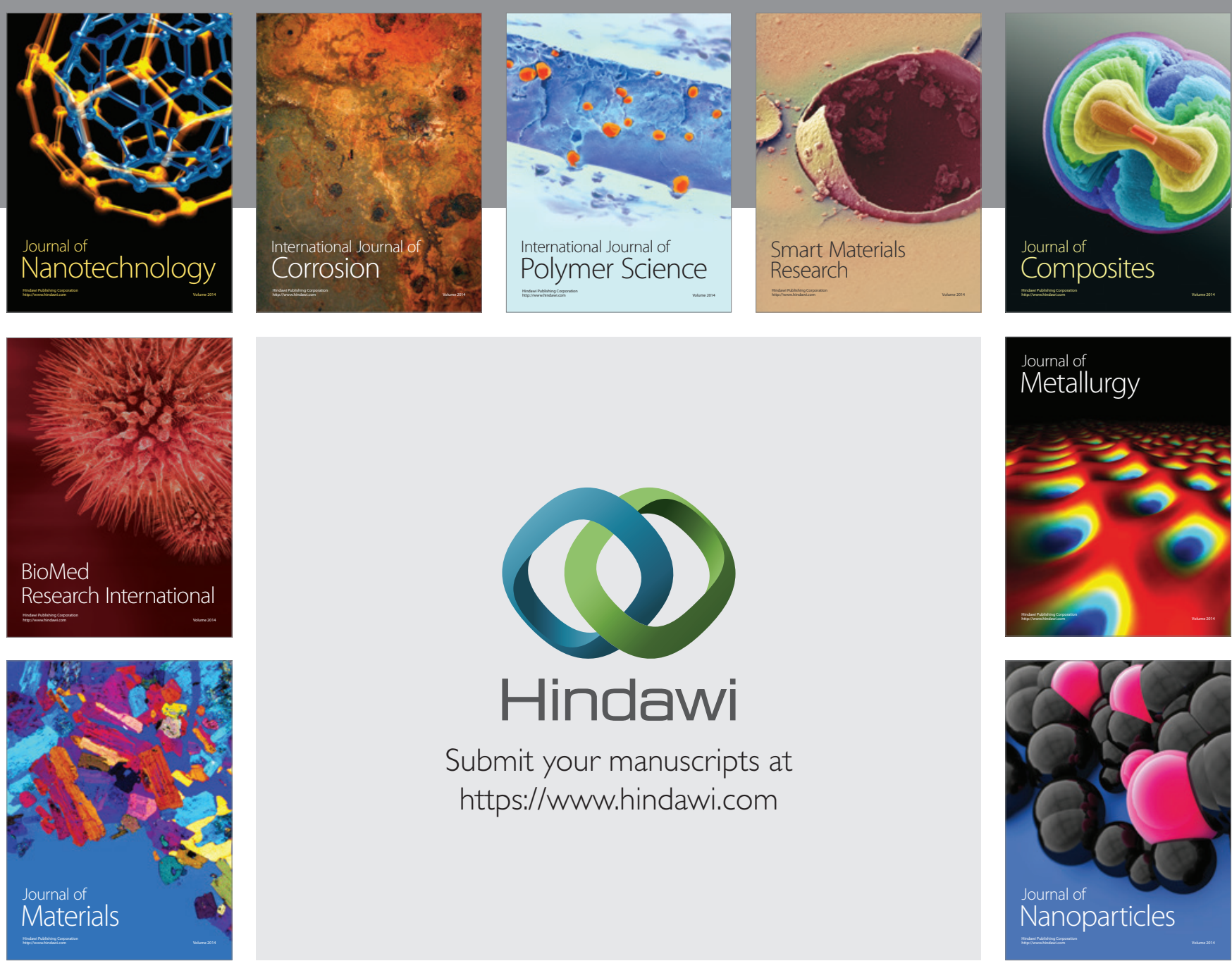

\section{Hindawi}

Submit your manuscripts at

https://www.hindawi.com

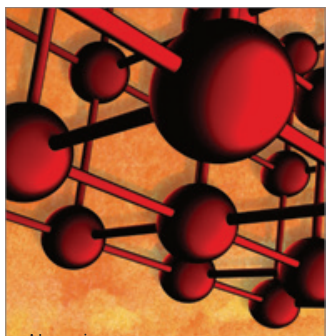

Materials Science and Engineering
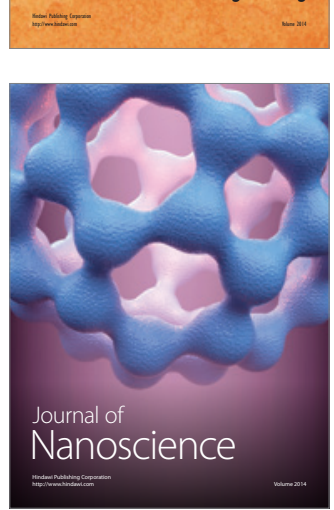
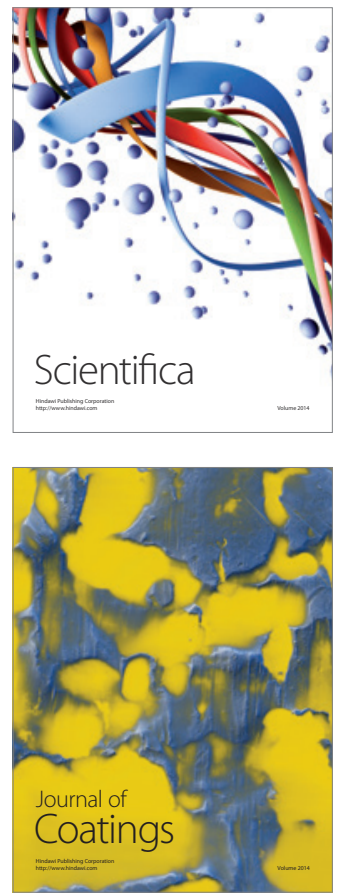
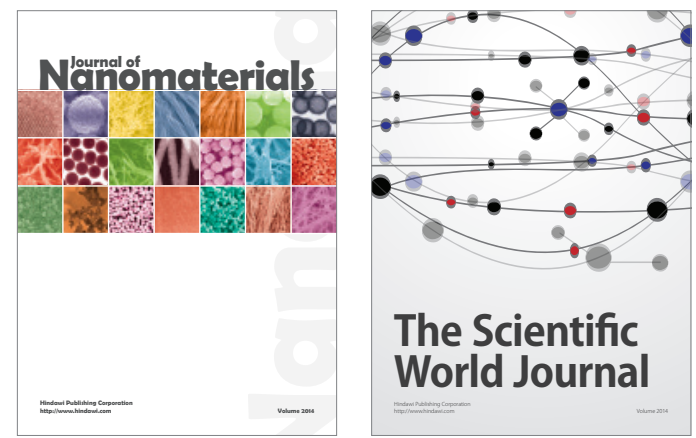

The Scientific World Journal
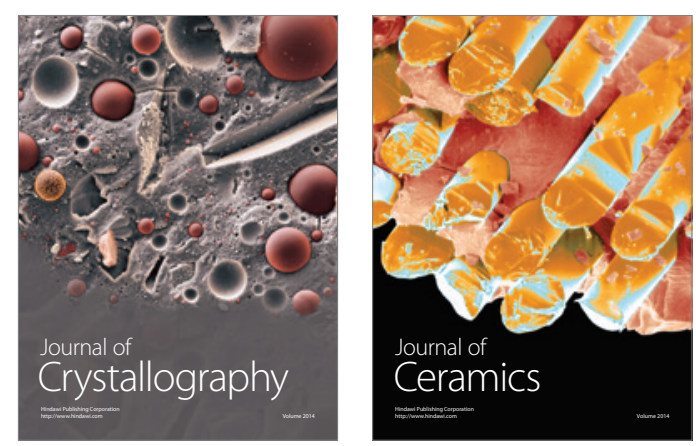
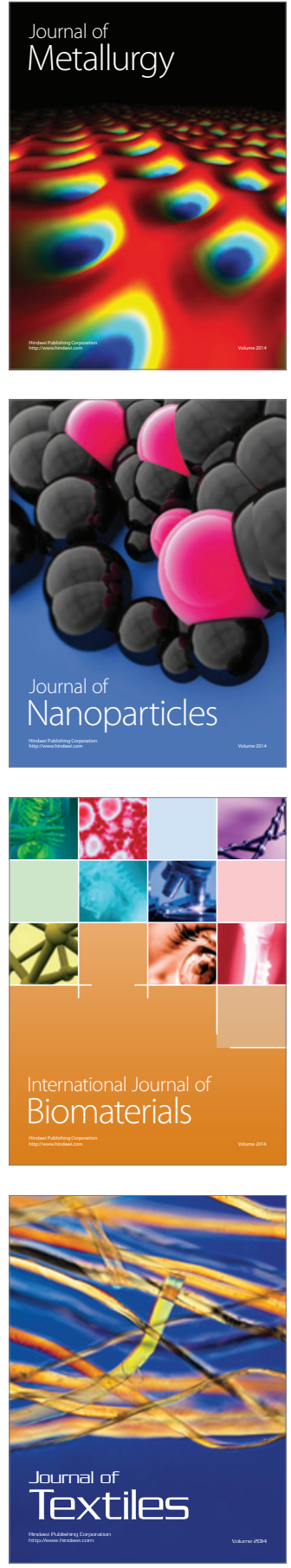